\title{
Investigation of an Alternative Fuel for Diesel Engines
}

\author{
A. $\operatorname{KEVEN}^{a}$ AND R. KARAALI ${ }^{b, *}$ \\ ${ }^{a}$ Golcuk MYO, Kocaeli University, Golcuk 41800, Kocaeli, Turkey \\ ${ }^{b}$ Department of Mechanical Engineering, Bayburt University, 69000 Bayburt, Turkey
}

\begin{abstract}
Internal combustion engines use generally fossil fuel products. World resources of it is limited. Renewable alternative energy sources are getting important solution for energy demand. Hazelnut oil ethyl ester is obtained from raw hazelnut and mixed with diesel oil in certain proportions to use in a four-stroke direct injected single cylinder diesel engine. In this study the effects of the mixture of diesel oil with hazelnut oil ethyl ester on the engine performance and exhaust gas emissions are investigated for the first time in literature. The fuel injection system is regulated to use the mixture in the engine for the investigation. The results show that, the mixture with $25 \%$ ethyl ester extracted from hazelnut oil can be used as an alternative fuel without any change or regulation of the diesel engine.
\end{abstract}

DOI: 10.12693/APhysPolA.128.B-282

PACS: 88.20.tf, 88.05.-b

\section{Introduction}

Turkey's oil reserves are insufficient. A large proportion of our oil needs are supplied from foreign countries. This situation leads to the search for new energy sources. One of this new energy sources are vegetable oils. Turkey can use of vegetable oils as a renewable energy source because it is an agricultural country. Nut cultivation in Turkey is carried out annually for 2500 years. Turkey has 350-600 thousand tons of annual production hazelnut which $65-70 \%$ of the world hazelnut production. Hazelnut has been found most suitable growing conditions in the Black Sea region of Turkey.

Vegetable oils can be used without any changes on the engine. The high viscosity of vegetable oils makes difficult to use as an alternative fuel. Vegetable oils are corn oil, cottonseed oil, linseed oil, peanut oil, rapeseed oil, sesame oil, soybean oil etc. Vegetable oils' viscosity are $30 \mathrm{~mm}^{2} / \mathrm{s}$ and more. The viscosity of diesel fuel used in compression ignition engines is about $3 \mathrm{~mm}^{2} / \mathrm{s}$. The viscosity of hazelnut oil is very similar to diesel fuel than any other vegetable oil. Many studies on the vegetable oils as an alternative fuel for diesel engines have been done. In these studies, sunflower, peanut, sesame, olive, palm, cottonseed, soybean, rapeseed, and esters of these oils are found usable and useful as an alternative to diesel fuel. He and Bao [1], has analyzed the rapeseed oil and diesel fuel mixture (30\% rapeseed oil, $70 \%$ diesel fuel) for operation in a single-cylinder diesel engine. Rapeseed oil as an alternative fuel source and with no change in the motor structure can be used as diesel fuel, but they stated that the high viscosity of rapeseed oil is a very important problem.

Rakopolulos in his research [2], has used 4-stroke, direct injection, and turbulent combustion chamber

\footnotetext{
*corresponding author; e-mail: rabikar@gmail.com
}

indirect injection diesel engine with the fuel that the percent ratio of 25/75 and 50/50 mixtures of waste oil and commercial diesel fuel. It is investigated that the mixture (diesel + olive oil) effects on exhaust gas emissions by analyzing the maximum pressure, the exhaust temperature, the exhaust emissions of nitrogen oxides $(\mathrm{NO} / \mathrm{NOx})$, the hydrocarbons $(\mathrm{HC})$, and the carbon monoxide $(\mathrm{CO})$. In the study it has identified the differences in engine performance and exhausts emissions of each parameter and compared with each other.

\section{Materials and methods}

The crude hazelnut oil has $8.46 \%$ saturated fatty acids, $81.19 \%$ monounsaturated fatty acids, and $10.35 \%$ polyunsaturated fatty acids. Some properties of the crude hazelnut oil are given in Table I.

Hazelnut oil ethyl ester is prepared in a home environment as follows.

1. 1 liter of hazelnut oil with half a liter of toluene $\left(\mathrm{C}_{7} \mathrm{H}_{8}\right)$ is mixed. This oil is made to solve the hazelnut oil;

2. Combined toluene soluble hazelnut oil is transferred to a 5 liter flask. 1 liter of $1 \%$ sulfuric acid per liter of the oil in ethanol is prepared containing the other hand. That is stirred with $99 \%$ ethanol and $1 \%$ sulfuric acid. The mixture is stirred in a 5 liter flask with toluene;

3. flask in which the mixture is tightly sealed. Placing the other end of the hose is sealed to the cover before the flask is allowed to outside;

4. prepared flask is heated at $60^{\circ} \mathrm{C}$ water bath heated to about 8 hours;

5. it is heated up to room temperature the mixture from the water bath. Then the inside of the mixture is stirred with $5 \%$ sodium chloride. $95 \%$ water 
and $5 \%$ sodium chloride is stirred in $5 \%$ sodium chloride. 2 liters of saline solution is used for 1 liter of oil;

6. the mixture of 1 liter of oil for 2 liters of $n$-hexane $\left(\mathrm{C}_{6} \mathrm{H}_{14}\right)$ is added. Then the mixture is heated for a period of phase formation;

7. the lower phase and the upper phase in two phases are formed. The lower phase and the upper phase are separated by separator funnel. The supernatants are placed on a container. The lower phases are discarded;

8. to the volume of the oil is added $2 \%$ sodium bicarbonate solution and mixed thoroughly. Phase separation of the mixture is done and allowed to rest.
Sodium bicarbonate solution is used to remove the corrosive effects of the fatty acids. Acid and other substances in the ester are allowed resting on the bottom of the container;

9. the phases formed after the lower phase has been taken with the aid of separating funnel. The water in the resulting ester must be cleaned for better combustion. The anhydrous sodium sulfate is added to the ester phase that are intensively mixed. The resulting things are dried;

10. the sodium sulfate is cleaned by using the resulting ester mixture through filter paper, and hazelnut oil ethyl ester is obtained.

Some properties of crude hazelnut oil.

\begin{tabular}{c|c|c|c|c|c}
\hline \hline Oil acids & $\begin{array}{c}\text { Mass } \\
\text { ratio [\%] }\end{array}$ & Formula & $\begin{array}{c}\text { The number of carbons } \\
\text { and double bonds }\end{array}$ & $\begin{array}{c}\text { Molar } \\
\text { mass }\end{array}$ & $\begin{array}{c}\text { Molar number } \\
(\text { mass } / \text { mol.mass })\end{array}$ \\
\hline Palmitic acid & 5.55 & $\mathrm{C}_{15} \mathrm{H}_{31} \mathrm{COOH}$ & $16 / 0$ & 256.42 & 0.0216 \\
Stearic acid & 2.66 & $\mathrm{C}_{17} \mathrm{H}_{35} \mathrm{COOH}$ & $18 / 0$ & 284.47 \\
Oleic acid & 80.79 & $\mathrm{C}_{17} \mathrm{H}_{33} \mathrm{COOH}$ & $18 / 1$ & 282.48 \\
Linoleic acid & 10.21 & $\mathrm{C}_{17} \mathrm{H}_{31} \mathrm{COOH}$ & $18 / 2$ & 280.44 & 0.2860 \\
\end{tabular}

TABLE II

Some physical and chemical properties of crude hazelnut oil, hazelnut oil ethyl ester and diesel oil.

\begin{tabular}{c|c|c|c}
\hline \hline & crude hazelnut oil & hazelnut oil ester & diesel oil \\
\hline Specific gravity g/ml & 0.915 & 0.803 & 0.830 \\
Viscosity (temp.) $\left[\mathrm{cSt}\left(\left[{ }^{\circ} \mathrm{C}\right]\right)\right]$ & $3.3(37.8)$ & $3.3(37.8)$ & $4.3(27)$ \\
Calorific value $(\mathrm{kJ} / \mathrm{kg})$ & 40170 & 50880 & 43000 \\
Flash Point $\left({ }^{\circ} \mathrm{C}\right)$ & 115 & 30 & 58
\end{tabular}

Some physical and chemical properties of crude hazelnut oil, hazelnut oil ethyl ester and diesel oil are given in Table II. The specifications of test bed Lombardini engine are as follows: model 6 LD 400, 1 cylinder four-stroke direct injection, cylinder bore $\times$ stroke $86 \mathrm{~mm} \times 68 \mathrm{~mm}$, cylinder volume $395 \mathrm{~cm}^{3}$, the compression ratio is $18: 1$, the maximum torque is $20 \mathrm{Nm}$ (2200 rpm), the injector spray pressure is 200 bar, and the minimum oil pressure is $10-15 \mathrm{~N} / \mathrm{cm}^{3}$. The elements of the set in the experiment are controlled before the experiment. The experiment has started with $100 \%$ diesel. Gas engine after reaching the given engine operating temperature is loaded with electrical dynamometer. Tests for the engine speed of $2600,2800,3000,3200,3400$, $3600 \mathrm{rpm}$ are performed by using fuel mixture in. Each engine speed measurements have been made in the stable operating conditions. In the experiments, the injection pressure is 200 bars. In the experimental results motor torque, effective engine power and exhaust emissions are measured.

\section{Results and discussions}

In this section, engine performance and engine speed changes depending on the number of exhaust emission values is shown in tables and graphs. Rates of ethyl ester and diesel fuel used in experiment were as follows: $100 \%$ diesel $(\mathrm{m}) ; 50 \%$ hazelnut oil ethyl ester (fe) and 50\% diesel (m); $75 \%$ hazelnut oil ethyl ester (fe) and $25 \%$ diesel (m); $25 \%$ hazelnut oil ethyl ester (fe) and $75 \%$ diesel (m); $100 \%$ ethyl ester of hazelnut oil (fe). The engine fueled with $75 \%$ fe mixture and $100 \%$ fe worked irregularly, therefore the emission and performance measurements could not be made. There was a separate lubrication system for precision-machined components of the injection pump, but some parts are 


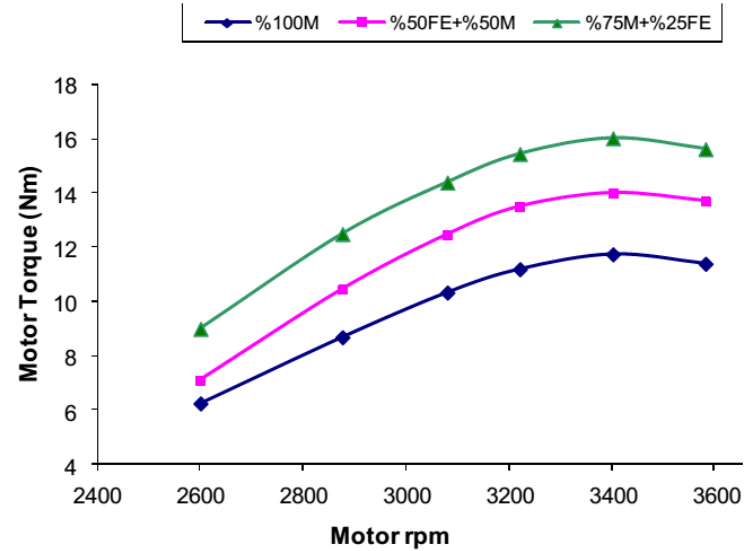

Fig. 1. Variations of motor torque with motor rpm. $\rightarrow \% 100 \mathrm{M} \rightarrow-\% 50 \mathrm{FE}+\% 50 \mathrm{M} \rightarrow \% 75 \mathrm{M}+\% 25 \mathrm{FE}$

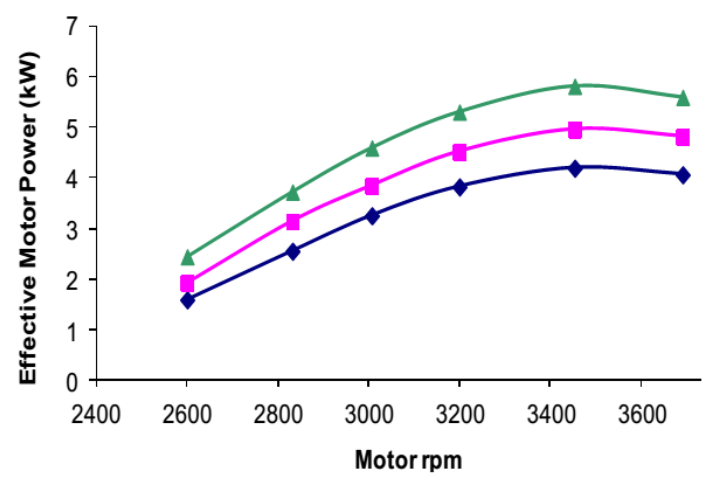

Fig. 2. Variations of effective motor power with motor rpm.

lubricated by the fuel itself. The viscosity of diesel fuel used in diesel engines is $4.3 \mathrm{~mm}^{2} / \mathrm{s}$ (for measuring temperature of $27^{\circ} \mathrm{C}$ ) ensures an appropriate value for the lubrication. Viscosity of tested oil ethyl ester is $0.894 \mathrm{~mm}^{2} / \mathrm{s}\left(\right.$ at $\left.37.8^{\circ} \mathrm{C}\right)$. Low viscosity degrades the lubrication of the pump. For better lubricating feeding pressure should be raised.
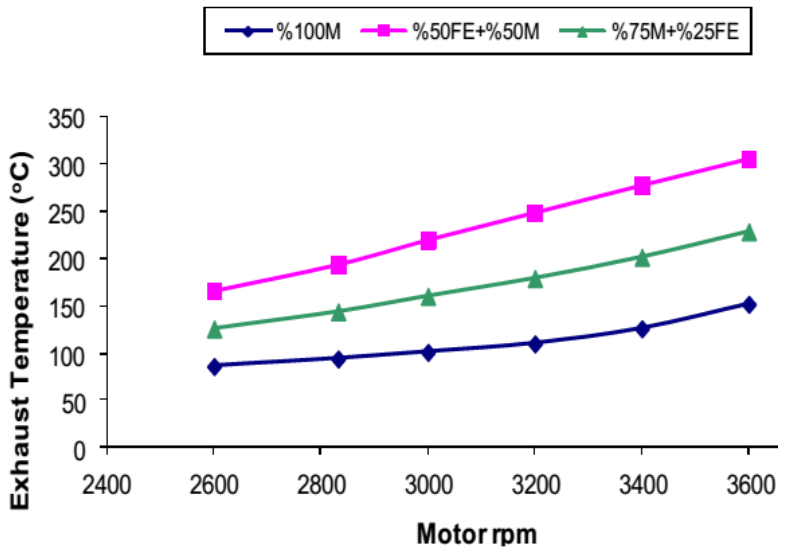

Fig. 3. Variations of exhaust temperature with motor rpm.

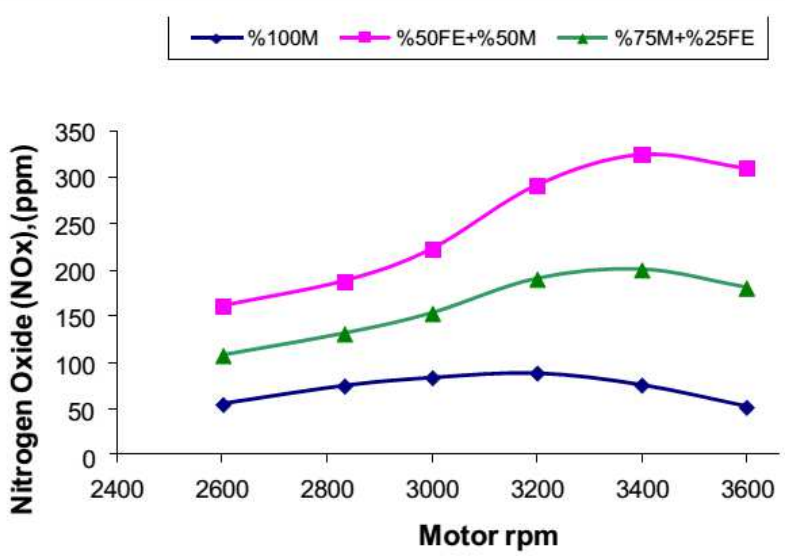

Fig. 4. Variations of nitrogen oxide with motor rpm.

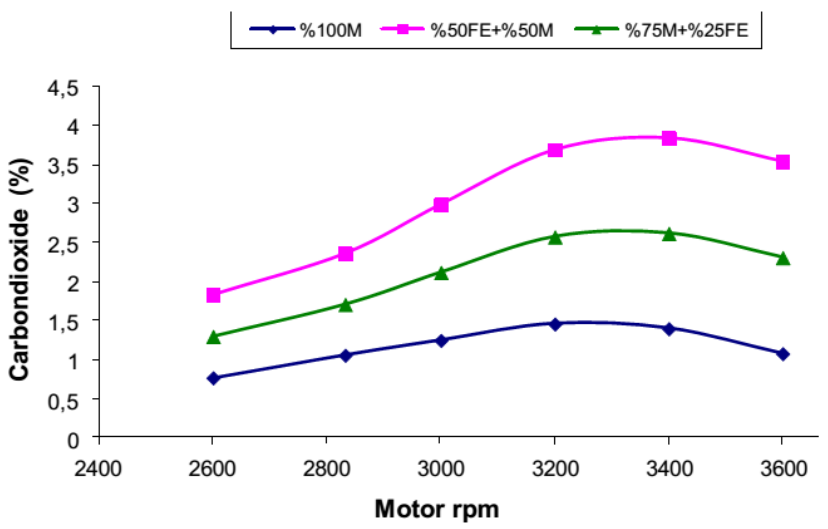

Fig. 5. Variations of carbon dioxide with motor rpm.

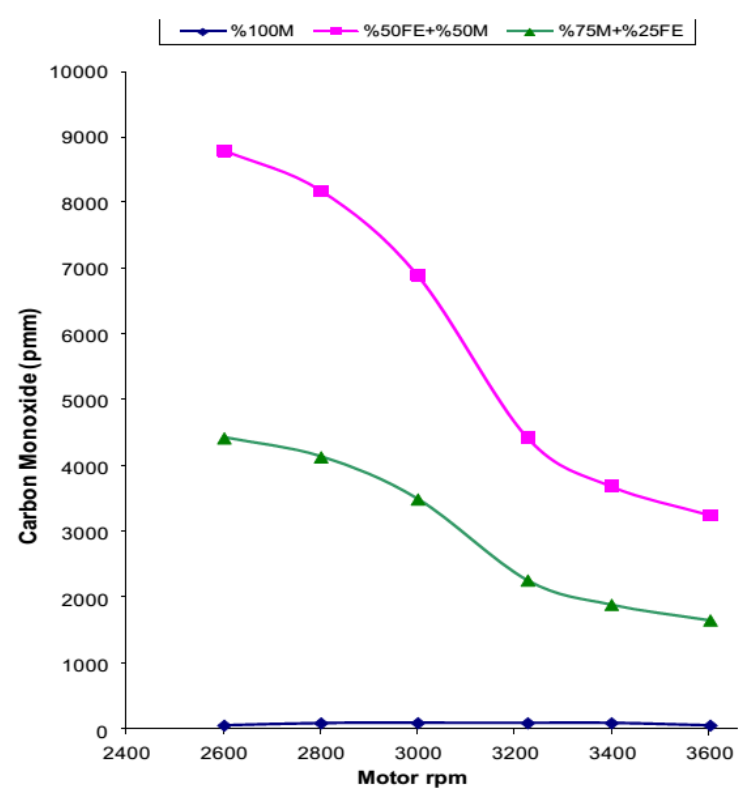

Fig. 6. Variations of carbon monoxide with motor rpm. 
Variations of motor torque with motor rpm are given in Fig. 1. It can be concluded that increasing engine rpm increases the motor torque. Variations of effective motor power with motor rpm are given in Fig. 2. As can be seen in Fig. 2 increasing engine rpm increases the effective motor power. Variations of exhaust temperature with motor rpm are given in Fig. 3. It can be concluded that increasing engine rpm increases the exhaust temperature. Variations of nitrogen oxide with motor rpm are given in Fig. 4. It can be seen in Fig. 4 that increasing engine rpm increases the nitrogen oxide. NOx emission depends on cetane number. Increasing cetane number decreases the NOx emission. Ethyl esters biodiesel and diesel cetane numbers are 53 and 57, respectively. Some studies reporting that fuels with high viscosity, density and iodine number cause more NOx emission.

Variations of carbon dioxide with motor rpm are given in Fig. 5. It can be concluded that increasing engine rpm increases the carbon dioxide. $\mathrm{CO}_{2}$ is an indicator of a complete combustion. The reason is the ester fuels have higher carbon content than the diesel. Normally increasing the engine rpm decreases the carbon dioxide, but in our experiment at low engine rpm poor combustion happened, unfortunately. Variations of carbon monoxide with motor rpm are given in Fig. 6. It can be seen in Fig. 6 that increasing engine rpm decreases the carbon monoxide. Carbon monoxide is the most important parameter of poor combustion. Ineffective mixing of air and fuel, locally rich zones in the combustion chamber, oxygen concentration required for oxidizing the $\mathrm{CO}$ to $\mathrm{CO}_{2}$ (post oxidation), and deficiency of time are the main reasons of high CO.

\section{Conclusion}

In this study, diesel oil and hazelnut oil ester is used in specific mixtures in a single-cylinder diesel engine. Engine performance measurements and emission tests of engine running at different load and speed were done for different kinds of fuel. The motor torque and power increase in regard to pure diesel fuel. The reason is hazelnut oil ester has higher energetic value than the diesel oil. When the fuel containing $75 \%$ and $100 \%$ hazelnut oil ester was used, the test engine runs erratic, because of the hazelnut oil ester low viscosity. Measurements for those fuels were not performed. Increasing hazelnut oil esters rate increases the energetic value of fuel. It increases the exhaust gas temperatures. The emissions of hazelnut oil esters mixture are higher than the diesel emissions. Some results can be concluded as:
1. hazelnut oil ethyl ester has lower viscosity than the diesel oil. Therefore appropriate quantity and pressure should be used for fuel injector at the diesel engine;

2. hazelnut oil ethyl ester has higher calorific value than diesel oil;

3 . without any change in the motor $25 \%$ hazelnut oil ethyl ester mixtures can be used as an alternative fuel;

4. hazelnut oil ethyl ester mixture has high value of $\mathrm{CO}$ emissions. Some kind of fuel additive should be used or the motor adjustments must be changed. To reduce NOx emissions the injected fuel particles must be adequatly dispersed;

5. fuel can be used with appropriate adjustments to the fuel injection system.

\section{References}

[1] Y. He, Y.D. Bao, Renew. Energy 28, 1447 (2003).

[2] C.D. Rakopolulos, Renew. Energy 2, 327 (1992). 